\title{
Oralidad, escritura y escrituralidad
}

\author{
Oral usage, writing and escrituralidad
}

\section{Rudy Mostacero*}

\section{Resumen ${ }^{1}$}

El propósito de este artículo es presentar algunas reflexiones en torno a la producción textual humana, actividad semiótica que relaciona el aprendizaje de la primera oralidad y la proyección de esta en todos los usos de la lengua; de igual modo, la utilización de las más variadas tecnologías de la palabra y de la imagen, esto es, la escritura y la cultura de la escritura. Pero esto no es más que un pretexto para poder explicar cuáles son los dos grandes constructos de la producción textual humana: la oralidad y la escrituralidad, conceptos necesarios para replantear la vieja relación entre oralidad y escritura, por una parte, y entre escritura y textualidad, por otra. El interés que pueda tener este conjunto de investigaciones, en el contexto de la lingüística, de la semiótica y de la psicología cognitiva, estriba en que se pueda llegar a entender mejor los límites entre pictografiar, grafizar, textualizary digitalizar, por una parte, necesarios asimismo para comprender la evolución de las "tecnologías de la palabra" (en el sentido de Ong, 1987), y por otra, de poder utilizar sus resultados para estudiar mejor la tipología de textos y discursos, que a la postre redundaría en ciertas aplicaciones pedagógicas y creativas.

Palabras clave: oralidad, escrituralidad, categorías de la textualidad, continuum cultural.

\section{Abstract}

The purpose of this article is to present some reflections about human textual production, a semiotic activity that relates the learning of the first oral usage and its projection in all language usages, also, the use of the most varied technologies of the word and the image, this is, writing and the culture of writing. But, it is just an excuse for being able to explain which are the two big tendencies of human textual production: the oral usage and the escrituralidad; concepts that are necessary to establish again the old relation between oral usage and writing, on one side, and between writing and textual production, on the other side. The interest that could have this set of investigations in the context of linguistics, semiotics and cognitive psychology, consists in the fact that the limits among making a graphic verbal delineation, tracing graphs, making textual productions and to digitalize, could be understood in a better way; which are, on one side, necessary to understand the evolution of the "technoligies of words" (according to Ong, 1987), and on the other side, to use its results to study the typology of texts and discourses, something that would redound in some creative and pedagogic applications.

Key words: oral usage, escrituralidad, categories of the textual production, cultural continuum.

* Profesor titular e investigador de la Universidad Pedagógica Experimental Libertador, Instituto Pedagógico de Maturín, con proyectos de investigación y publicaciones en las áreas de pedagogía del discurso, competencias y dificultades de escritura, semiótica y oralidad. Universidad Pedagógica Experimental Libertador. Instituto Pedagógico de Maturín, Venezuela. Correo: ben_mos2@yahoo.com

1 Este artículo fue publicado por primera vez en la revista Sapiens (2004) y se reedita aquí con autorización del autor y del editor. Se ha conservado la estructura inicial, aunque el texto fue revisado y se le introdujo una sección nueva: "Oralidad, escritura y alfabetización". 


\section{La oralidad en el individuo y en la sociedad}

La oralidad es el primer sistema comunicativo que adquiere el individuo dentro de esa actividad semiótica compleja que es la producción textual y discursiva. Es la primera experiencia interactiva porque surge con la vida y se repite cada vez que nace un niño o una niña. Gracias a ella el ser humano se diferencia de los animales y lo hace desde el punto de vista verbal, cognitivo, neurolingüístico y semiótico, pero, con el añadido de las tecnologías, el hombre se diferencia aún más, y por eso se han creado una serie de "herramientas" de la información y de la comunicación que otros seres vivos no son capaces de utilizar.

La oralidad consiste en un sistema triplemente integrado, constituido por variados componentes verbales (emisión sonora, decodificación semántica, combinatoria sintagmática, elementos paraverbales, entre otros), por un repertorio kinésico y proxémico y por un sistema semiótico concomitante (dimensión cultural). Por eso mismo, pertenece a un triple plano: un plano verbal o lingüístico, un plano paralingüístico y un plano semiótico-cultural. Esto, lógicamente, determinará la inmensa variedad de posibilidades de comunicación, así como la riqueza de formas y registros, lo cual redunda en textos híbridos y polifónicos. Desde el punto de vista de un teórico de la comunicación, el campo se organizaría en términos de modalidades discursivas y casos de polifonía discursiva; desde el punto de vista de un analista del discurso, el interés se centraría en las estrategias de cortesía o en el contenido ideológico. Sea como fuere, el tema de la oralidad rebasa los confines de la escritura y requiere de la inserción de un nuevo constructo: la escrituralidad, tal como se examinará más adelante.

La oralidad es una realidad coloquial, tautológica y evanescente. Coloquial porque se construye en la in- teracción espontánea, cotidiana; tautológica, por su carácter repetitivo y reiterativo, con escasos márgenes para la originalidad; y evanescente, como lo precisó Ong (1987, p. 38), porque "el sonido sólo existe cuando abandona la existencia. No es simplemente perecedero sino, en esencia, evanescente". Por tanto, se diferencia de la producción verbal institucional, académica o formal, que se basa en la escuela y la lectoescritura. Está, asimismo, muy ligada al discurso conversacional y narrativo, por su fluencia natural, y al ámbito familiar y de la intimidad; sin embargo, insertada como está actualmente en las comunicaciones de telefonía celular y de la escritura digital, el usuario ha tenido que inventar nuevas normas para el contacto cara a cara y nuevas formas de gestualidad. Eso indica que a pesar de las innovaciones tecnológicas la oralidad tiene y seguirá teniendo un espacio semiótico propio y preponderante.

Para el niño o la niña que aprende a hablar, la oralidad se construye con materiales eminentemente familiares y coloquiales, pero una vez que se proyecta de la familia a la comunidad, su oralidad se hace polilectal. Primero interactúa dentro de su comunidad de práctica, luego aprende las normas de la comunidad lingüística, regional o nacional. El aprendizaje se consolida cuando el infante ingresa a la educación formal, primero en los aprestos de la alfabetización inicial y, años después, en cada uno de los escenarios donde se da la alfabetización académica (como lector y productor de textos). Pero hay un hecho incontrastable, la oralidad cabalga todas las tecnologías.

La oralidad del infante coincide con la oralidad primaria individual, por ser experiencia personal y socializadora, si se mira, sobre todo, desde el punto de vista de su adquisición temprana. A esta hay que añadir la oralidad primaria colectiva o social que en unos casos puede corresponder a una sociedad del todo o parcialmente ágrafa y en otros a una sociedad urbana, ligada, por supuesto, a tecnologías de escri- 
tura. En este último caso la llamaré oralidad secundaria urbana y se caracterizará por su vínculo con la escuela, con las técnicas de producción, circulación y consumo de textos; por la intertextualidad; y por haberse abolido las limitaciones de tiempo y espacio (Internet de banda ancha). No obstante, si he tomado el término "oralidad primaria" de Ong (1987) no lo uso exactamente con el mismo significado que le da este autor y, por lo tanto, no comparto su acepción. Ong dice: "La oralidad aquí tratada es esencialmente la oralidad primaria, la de personas que desconocen por completo la escritura" (p. 15) y apela a "los seres humanos de las culturas orales primarias, aquellas que no conocen la escritura en ninguna forma" ( $p$. 18). Como puede verse, el autor alude a una oralidad pura que para nuestro momento histórico es difícil de convalidar. Por consiguiente, de acuerdo con mi manera de ver el problema, entiendo que la oralidad se presenta de tres maneras o clases:

1. ORALIDAD PRIMARIA INDIVIDUAL: del niño o niña que aprende la lengua materna, de 0 a 3 años aproximadamente, sin importar el tipo de sociedad en la que vive, es decir, si es indígena, rural o urbanizada. En otras palabras, la experiencia personal de apropiación de la lengua materna.

2. ORALIDAD PRIMARIA COLECTIVA: de niños y adultos, la cual pertenece a sociedades predominantemente orales, que viven al margen de una cultura letrada, como las sociedades indígenas de América, pero que no están exentas de contactos permanentes o esporádicos con cualquier elemento de la cultura de la escritura.

3. Oralidad SECUndaria uRbana: dependiente de los mass-media, la escuela, las instituciones, las empresas, la banca, los partidos políticos, etc., donde se mezcla con las más sofisticadas tecnologías de la información y de la comunicación, y donde lo característico es la invención de nuevos soportes y dispositivos, nuevas variedades de oralidad, pero a partir de la hibridación con las variedades de la escrituralidad.

Por eso, la oralidad de un bebé, balbuceante y holofrástica, puede convivir en la misma sociedad con la oralidad digitalizada, siendo posible pasar y volver de una a otra sin limitaciones de tiempo y espacio, aun cuando se tome como referencia un grupo humano muy tradicional. En consecuencia, todo cuanto se viene argumentando se refiere al constructo teórico de la oralidad, pero la actividad semiótica no depende solo de esta experiencia comunicativa. Existe otra realidad, aparentemente contraria, que ha sido identificada con la escritura o las "tecnologías de la escritura”. Empero, no es lo mismo relacionar y contrastar la oralidad con la escritura, con la cultura de la escritura o con las tecnologías de la escritura.

Los teóricos de la oralidad que se basaron en las investigaciones del pionero Milman Parry, quien se interesó por la época homérica con el objeto de estudiar las condiciones de producción escrita de las epopeyas de Homero, dentro de un mundo y de una tradición que eran predominantemente orales, contribuyeron a forjar la tesis de que la "palabra hablada" se debía oponer a la "palabra escrita". Los continuadores de Parry, siempre en Inglaterra, es decir, Albert Lord, Eric Havelock, el hijo de Milman Parry, Adam Parry, y otros, se refirieron a la relación entre la cultura de tradición oral y la cultura erudita que convivieron en la época de Homero; sin embargo, no se pueden extrapolar de la misma manera dichas categorías al tiempo histórico de Millman Parry. Por eso conviene diferenciarlas, como lo estoy haciendo aquí, para liberarlas incluso de la visión eurocéntrica, que algunos autores les asignaron a las sociedades alfabetizadas, como superiores a las sociedades ágrafas. Para detalles más precisos sobre los estudios de Parry, remito a Ong (1987, cap. II, "El descubrimiento moderno de las culturas 
orales primarias") y al excelente resumen de Pacheco (1992, cap. 1, "Hacia una teoría de la oralidad"). Similarmente, a los trabajos de Jack Goody, The Domestication of the Savage Mind (1976), al volumen compilado por este mismo autor Cultura escrita en sociedades tradicionales (1996) o a Cultura escrita y oralidad, compilado por Olson y Torrance (1998).

No obstante, como ya lo señalé, no es la escritura la que se opone a la oralidad, ni siquiera un término más genérico, como cultura escrita, utilizado, por ejemplo, por Goody (1996). Un vocablo más complejo, como "antropología de la escritura", empleado por Cardona (1999), tampoco lo es, ni la complejidad de acepciones con las que Desbordes (1995) estudia la escritura en la Antigüedad romana. Para eso hay que recurrir a un constructo que yo identifico con el nombre de escrituralidad. El mismo viene envuelto en un neologismo y ya se sabe que todo neologismo produce algún escozor; sin embargo, hay razones suficientes para emplearlo en este contexto. La definición y la pertinencia del término se examinarán más adelante, en la tercera sección. En lo inmediato examinaré las experiencias históricas que el hombre ha tenido con la escritura, desde la pictografía hasta la escritura digital, con el objeto de argumentar a favor de la pertinencia de dicho neologismo.

\section{Experiencias con la escritura}

La manera inédita y ciertamente vacilante como un niño o una niña toman un instrumento de escritura para aprender a caligrafiar sus primeras letras recuerda el modo arcádico de cómo los hombres de la Antigüedad hicieron la invención, primero, de los primeros instrumentos y materiales para poder escribir y, segundo, de los sistemas de escritura. Entre ambos hechos se puede interponer miles de años de distancia y, sin embargo, cada vez que un párvulo inicia su alfabetización la experiencia trans- curre por los mismos estadios de evolución de la escritura como tecnología: de los pictogramas a los símbolos fonográficos. Esta es una correspondencia que en materia de lenguaje se puede constatar en la experiencia humana. Entre las altas culturas y civilizaciones de la Antigüedad, la escritura evolucionó de un sistema pictográfico a un glotográfico y, luego, dentro de este, de un logográfico a uno alfabético (Sampson, 1997).

Y como se trata de experiencias, en este lugar se desea reflexionar sobre cuatro modalidades que están presentes en la acción de representar. Dichas prácticas reciben el nombre de pictografiar, escribir, grafizar y digitalizar y será inevitable relacionarlas, primero, con las dos maneras de textualizar la experiencia humana ( $\mathrm{y}$, con esto, tendremos oportunidad de volver al problema de los constructos teóricos ya aludidos) y, segundo, con los sistemas notacionales de representación y los de grafización.

\section{Otras prácticas discursivas}

El propósito de esta sección es el de demostrar la existencia de otras prácticas discursivas distintas del "escribir", en el sentido de prácticas semióticas más complejas y ligadas a alguna tecnología. Cuando se examina la cantidad de términos de que se dispone para aludir a la actividad de trazar marcas o señales sobre un determinado soporte, siempre se identifica esta experiencia como una experiencia de escritura. Sin embargo, el término ha sido desbordado por la diversidad de prácticas y "escribir" ya no constituye la única manera de "representar simbólicamente algo" ni, sobre todo, de integrar en un mismo concepto la diversidad de modos y formas de comunicar la experiencia humana.

Una cosa es redactar un mensaje de pésame, otra trabajar en el arte final de un cartel para un congreso, otra diferente elaborar un boceto del plano de 
un edificio y, por último, construir la página web de una revista científica. Evidentemente, con estos pocos ejemplos se puede llegar a demostrar que el significado de "escribir" (en sentido lato) solo es aplicable al primer caso, ya que en los demás intervienen otros tipos de elementos (imágenes, colores, dibujos, íconos, entre otros) que rebasan los parámetros de la escritura canónica. En lo que sigue me propongo, por un lado, hacer un análisis de cuatro posibilidades que hay para expresar algo mediante marcas o caracteres visuales y, por otro, argumentar cómo se diferenciarían los conceptos de escribir y de escritura al considerar otros términos como pictografiar, grafizar, textualizar y digitalizar. Esto permite apreciar que el término escritura adquiere un estatus diferente del de "oralidad", pero también señala que dentro de su campo conviven otros fenómenos semióticos que van de la escritura analógica a la digital y que están más allá de la escritura convencional. Por tanto, no es cierto que la oralidad se oponga a la escritura, sino que forman parte de un mismo continuum, como lo explicaré más adelante.

La función esencial, la de representar y simbolizar, es la misma; por tanto, es una función semiótica universal, y es poseída por una marca, un símbolo, un ícono, una notación, un grafo, etc. En todos los casos la función representacional permite sustituir un objeto o idea de la realidad por un objeto que semióticamente se ha dado en llamar señal o signo. $\mathrm{Y}$ en esto también se basa el recurso de modelizar la realidad a partir del lenguaje (Lotman y Escuela de Tartu, 1979). La gran variedad de motivos queda atrapada en la red de señales que los lingüistas han clasificado atendiendo a la naturaleza del significante, por ejemplo Greimas (1971), y esto pudiera ser un aporte para resolver el problema de la tipología de los signos (intentada por Schaff, 1966; Eco, 1976, 1980, 2000; Mounin, 1972; Rossi-Landi, 1976; Peirce, 1974; entre otros). Pero cuando se vuelve al problema de las prácticas discursivas y se estudia la posibilidad de insertarlas dentro del campo de la "escritura", resulta infructuoso porque se trata de prácticas más complejas e híbridas.

\section{Escribir y hacer pictografías}

De acuerdo con Sampson (1997), la escritura en sus orígenes se divide entre el sistema que representa palabras (logográfica) y el que representa segmentos, sean sílabas o fonemas (fonográfica), las cuales quedan integradas, a la vez, en un sistema que el autor llama glotográfico, es decir, que permite simbolizar los enunciados orales de la lengua. Esto da pie a Sampson para diferenciar entre sistemas glotográficos y sistemas semasiográficos, primero, como las dos grandes modalidades de la escritura a través de los tiempos y, segundo, en el sentido de plasmar de modo directo alguna idea o acontecimiento de la realidad. Pero la exacta diferenciación entre lo glotográfico (que evoca la glotis, lo glótico, lo verbal, etc.) y lo semasiográfico, que para el lingüista inglés indica la oposición entre escritura y no escritura, no queda del todo clara.

Pues bien, "semasiográfico" no solo descansaría en una concepción glotocéntrica de la escritura, sino en una acepción particular de la palabra semasiología, de uso muy especial entre ciertos lingüistas alemanes y cierta tradición lexicológica ligada al estructuralismo de la palabra. Para empezar, el término fue propuesto y acuñado por Reisig hacia 1825 para referirse al estudio del significado lexical (estructura del léxico, relaciones entre sus elementos, derivación y cambio de lexemas, etc.) y opuesto, además, a la onomasiología (cfr. Lewandowski, 1992, p. 310). Quiere decir que el término no es muy feliz para referirse a lo que pudiera ser una protoescritura o una negación de la escritura. Incluso la consideración dicotómica de esta premisa no cuadra con la evolución no rectilínea de la escritura. 
Igualmente, Sampson descarta el término "escritura pictográfica" cuando dice: "otro término del lenguaje cotidiano que vale la pena mencionar aquí para rechazarlo por confuso es 'escritura-pintura' o 'pictografía"' (1997, p. 50). Sin embargo, no estoy de acuerdo con su posición, me parece legítimo emplear dicho vocablo, y por eso lo incluyo en este artículo. Otro autor (Tusón, 1997), que a su vez se basa en Sampson, también lo da como legítimo. Por su parte, Tusón, apoyándose en la concepción peirceana de la clasificación de las señales (en indicios, íconos y símbolos) advierte la manera gradual como se pasa de las señales naturales (el humo, la fiebre o las nubes) a las icónicas (un dibujo, una fotografía, una estatua, etc.) y a las simbólicas (los números, las letras, etc.).

Precisamente, la diferencia entre las escrituras simbólicas (que detentan mayor grado de arbitrariedad) y las icónicas (que se sustentan en un mayor grado de motivación) es lo que autoriza una distinción entre formas de representación arbitrarias y convencionales, respecto de las formas cuya preponderancia es la motivación referencial directa. Es decir, escrituras pictográficas y logográficas, como las entendemos aquí. Voy a detenerme en el concepto de pictografiar.

Pictografiar es hacer pictogramas o pictografías, esto es, representar ideas con figuras, dibujos, íconos o grafos, dentro de un espectro variado de convencionalidad, desde las que se basan en solo dibujos rupestres hasta los mensajes que incluyen números, letras, dibujos o íconos, como en la señalización urbana. Por ejemplo, la figura de una cabeza de buey (como en la escritura cuneiforme) o un triángulo con el vértice hacia abajo y una línea vertical en el centro (que en las antiguas culturas amazónicas venezolanas significaba el órgano sexual femenino). Pero asimismo, la "carta" enviada a un joven por una muchacha de la tribu yukaghir del nordeste de Liberia, donde se plasma todo un texto argumentativo y amenazador utilizando únicamente dibujos hechos por alguien que no sabe escribir (Sampson, 1997, p. 40) o la serie de figuras mudas, de uso comercial, que instruyen acerca de cómo armar un aparato (p. 45).

Debido a la evolución, los pictogramas devinieron en formas de escritura logográfica, lo cual ocurrió en todas las altas culturas de la Antigüedad: lo figurativo coincide o es sustituido por representaciones más sintéticas y, sobre todo, estilizadas, que van de ideas complejas a palabras (logogramas) o nombres de letras (fonogramas), tal como ocurrió con la cabeza de buey entre los sumerios. Aquello que significaba "tal cantidad de cabezas de ganado vendida a X" se convirtió en la representación de la forma fonética /gu/, que en sumerio expresaba solamente "buey", para acabar simbolizando a "Aleph", el nombre de la primera letra de la palabra. Esto es lo que se llama "principio de acrofonía", donde escribir equivale a "dibujar cosas para simbolizar" sus sonidos iniciales (Sampson, 1997, pp. 114 y ss).

De modo que entre pictografiar y escribir hay una evolución natural: el paso de lo puramente figurativo a lo simbólico, de lo ideográfico a lo fonográfico. Esto se cumplió en las lenguas de la familia semítica, así como en las proyecciones modernas que tuvieron el árabe y el hebreo actuales. En consecuencia, escribir es una actividad más evolucionada y compleja que pictografiar, pero grafizar lo es aún más. Entraña trascender o transponer la representación de la lengua oral, en el sentido de que con la acción de grafizar es posible dar a conocer la semiosis derivada de la ciencia, el arte y la tecnología, donde necesariamente se integran, por ejemplo, las artes gráficas, la xilografía, la holografía, etc.

Incluso, por ser un término más amplio, incluye los conceptos de notación y notacional (cfr. Tolchinsky, 1993) y, por consiguiente, da origen a los sistemas de notación y a los sistemas de grafización. Estos, como es lógico, son diferentes de los sistemas históricos de 
Tabla 1: Sistemas históricos de escritura y escrituras especiales

1. Sistemas históRICOS DE ESCRITURA: Cuneiforme, jeroglífica, china, americana (maya, de la Isla de Pascua, etc.), silábica (o silabográfica), alfabética (o fonográfica) y digital (con sus respectivos instrumentos y soportes de escritura).

2. Escrituras espeCiales (o de SEGUnda Generación): Alfabeto Morse, Braille, Pitman, esperanto, etc.; Alfabeto Fonético Internacional; lengua de señas; comunicación massmediática (linotipia, teletipia, telecable, transmisión satelital, video conferencia, video clip, etc.); sistema de señales (camineras y de tránsito, publicidad mural, televisiva, en vallas, cinematografía, etc.; señales de radio y televisión interespaciales, etc.).

escritura (cuneiforme, jeroglífica, china, americana, etc., y de las escrituras especiales y/o artificiales, como los alfabetos Morse, Braille, Pitman, el Alfabeto Fonético Internacional, el esperanto, etc.). Para una mejor identificación, véase en la tabla 1 la diferencia entre sistemas históricos de escritura y las escrituras especiales o de segunda generación:

Siguiendo ahora con lo notacional, veamos cómo entiende Tolchinsky la capacidad notacional. Se trata de una capacidad estrictamente humana que mediante el empleo de herramientas permite "dejar trazas permanentes de actos intencionales" (1993, p. 131), sea con fines estéticos o de cómputo, como ocurrió con los primeros homo sapiens que dejaron representada su habilidad para notacionar. Entonces, esta forma de representación implica una intencionalidad, el uso de cierta simbología y de utensilios de grabación. Desde luego, la representación notacional puede ser expresada de manera icónica o no. Pero, dentro de las diferentes formas de simbolización, la capacidad notacional se diferencia de la capacidad de escribir, ya que trasciende el ámbito de los grafemas. Lo notacional, al basarse en los números, las

Tabla 2. Sistemas notacionales y de grafización

SISTEMAS NOTACIONALES DE REPRESENTACIÓN:

- Unidades notacionales básicas: número, letra, nota musical, figura geométrica, imagen, dibujos estilizados, ícono, símbolo, etc.

- Lenguajes científicos y artísticos: lenguajes de ciencias como biología, matemática, física, química, estadística, lógica simbólica, entre otras; heráldica, numismática, filatelia, artes del fuego, pop art, art deco, tatuaje, etc.

SISTEMAS DE GRAFIZACIÓN:

- Grafización y arte: acuarela, aguafuerte, serigrafía, grabado, litografía, holografía, tomografía, pintura figurativa y abstracta, vanguardismo, artes gráficas, publicidad artística, etc.

- Tipología de discursos: géneros académicos.

- Modalidades del discurso: expositivo, narrativo, conversacional, argumentativo, instruccional, etc.

- Lenguajes electrónicos: de programación, wordstar, hipertexto, hipermedia, telefonía celular, animación electrónica, etc.

- Documentación y archivo: bibliotecas, hemerotecas, mapotecas, videotecas, fonotecas, bases de datos, centros de documentación, páginas web, revistas virtuales, etc.

- Representación visual: radiología, electrografía, ecografía, reprografía, retroproyección, video-beam, espectrografía, tomografía, etc.

- Escritura musical.

- Iconografía.

- Estatuaria.

- Arquitectura.

- Sistemasdemodelizacióndelmundo:construccióndemodeloscientíficosytecnológicos, teorías, paradigmas,entreotros. 
Tabla 3. Lugares e instituciones que "tutelan" la semiosis

- Museos de sitio (cuevas, criptas, panteones, cementerios, etc.), museos (de arte, del transporte, taurinos, etc.), yacimientos arqueológicos, etc.

- Bibliotecas, hemerotecas, logotecas, archivos, centros de documentación e información, librerías, multimedia, discotiendas, planetarios, etc.

- Instituciones educativas: jardines de infancia, escuelas, universidades, academias, educación a distancia, etc.

- Instituciones públicas: alcaldías, gobernaciones, asambleas, cabildos, congresos, conventos, cooperativas, tribunales, juzgados, registros, iglesias, ministerios, asociaciones, sindicatos, empresas, etc.

- Instituciones recreativas: estadios, coliseos, anfiteatros, teatros, hipódromos, gimnasios, etc.

notas musicales, las figuras geométricas, los dibujos estilizados, los símbolos de las ciencias puras y formales, los íconos, entre otros (ver Lewandowski, 1992, p. 243), se diferencia de las señales que alimentan los sistemas de grafización. Estos, por su parte, incluyen las señales audiovisuales, informáticas, ecográficas, holográficas, etc. Una clasificación no exhaustiva tanto de los sistemas notacionales como de los de grafización puede verse en el Cuadro 2:

Pues bien, si existe una distinción conceptual entre "escribir" y "notacionar", y entre "escribir" y "grafizar", esta sería la diferencia entre escritura y cultura de la escritura, ya que esta última comprendería todas las tecnologías de la palabra impresa y sonora, la imagen estática o en movimiento, más el añadi- do de la música, los efectos especiales, etc., es decir, un campo más vasto que el referente para "escritura". Ahora bien, cada uno de estos sistemas genera productos que existen durante el intercambio entre los usuarios, para los cuales, además, se han creado instituciones cuyo fin es resguardar, administrar o exhibir dichos productos. Son las instituciones que "tutelan" la semiosis, algunas de las cuales aparecen en el Cuadro 3:

Habiendo partido del propósito de diferenciar oralidad de escritura se ha llegado, casi sin advertirlo, a divisar la dimensión semiótica de la escrituralidad, es decir, esa dimensión de significación integrada por varias clases de sistemas, del más sencillo al más complejo, donde, como se aprecia en la Figura 1,

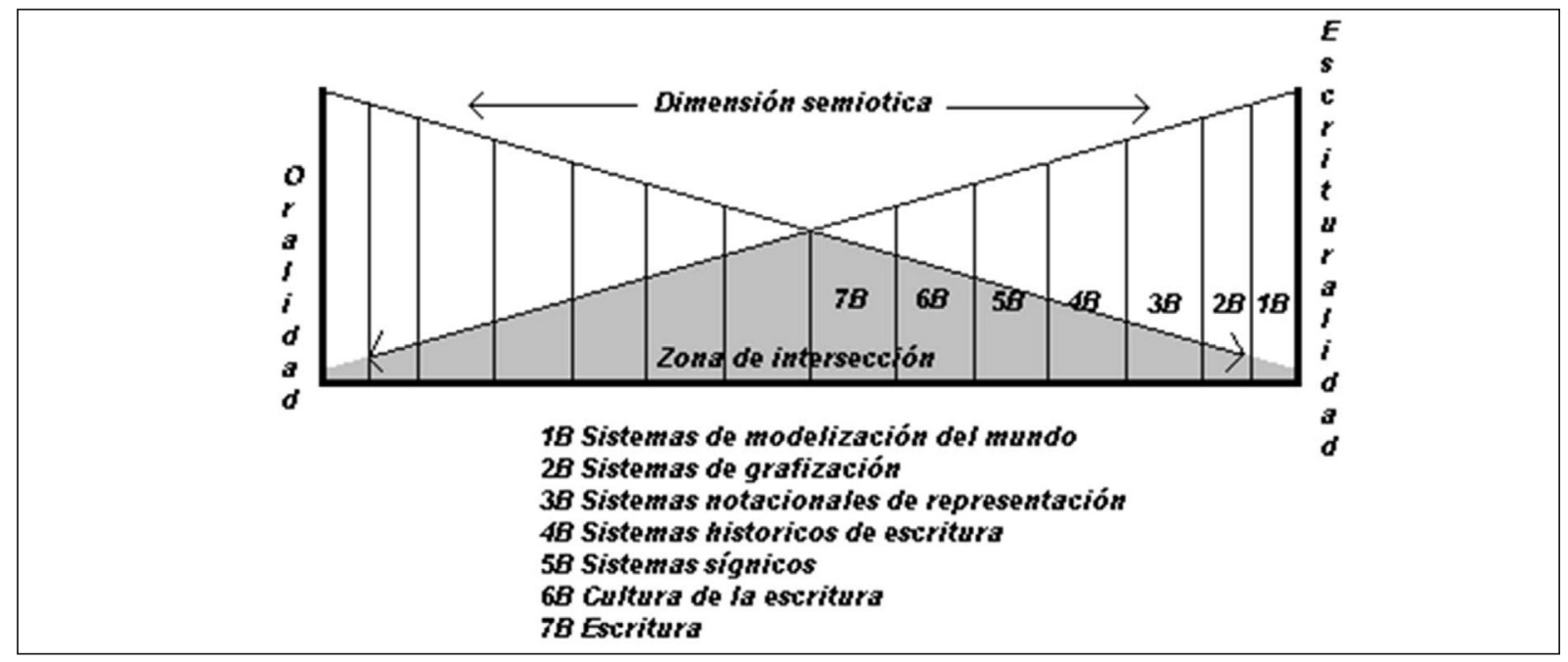

Figura 1. Dimensión semiótica 
unos contienen a otros, de la siguiente manera: 7B está contenido en $6 \mathrm{~B}$ por ser más reducido, $6 \mathrm{~B}$ en $5 \mathrm{~B}$, por la misma razón, y así sucesivamente. Esto, a la postre, demuestra una vez más que "escritura" no se opone al resto del campo semiótico de la oralidad (que tiene sus celdas vacías). No existe oposición, sino complementación, si se entiende que tanto la oralidad como la escritura y la escrituralidad forman parte de las manifestaciones de la comunicación humana y del uso de dispositivos y de soportes que hacen más variada y más rica la interacción cotidiana.

\section{La escritura electrónica}

Por último, solo hace falta que me refiera a la cuarta manera de comunicar la experiencia humana: la digitalización. Para situarla en el justo lugar que le corresponde es conveniente separar las formas y especies de la comunicación analógica (caracterizadas por la linealidad) de las digitales, las cuales pertenecen a otro paradigma comunicativo. Al cambiar el soporte, se incorporan la red (Internet), la multimedia, las relaciones hipertextuales y toda una generación de dispositivos digitales: ipod, teléfono celular, cámara digital, escáner, entre otros. Gracias al hipertexto, el cibernauta puede "construir un texto predispuesto a multitud de enlaces y conexiones con otros textos y donde el trayecto o recorrido de lectura está igualmente liberado a los propios intereses del lector de turno" (Rodríguez, 1999, p. 15). Por eso es una "herramienta tecnológica" válida, por las reconfiguraciones textuales y por las múltiples convergencias y divergencias discursivas y semánticas (Landow, 1995, p. 27). Se trata de un "híbrido cultural" (Rodríguez, 1999, p. 185 y ss) donde los recursos de multimedia han terminado por romper la linealidad de la escritura y dan paso a una "virtualidad" sin soportes contables, atómicos, como los segmentos de la voz o de la escritura convencional.
El crecimiento de Internet ha sido colosal: "En el mundo hemos pasado de un puñado de servidores en 1989 a cerca de 70.000 nodos a mediados de 1995. El tráfico en la WWW creció 444\% en 1993 y $1.713 \%$ en 1994 [...]. A mediados de 2001 tenemos 430 millones de personas en Internet y cerca de 35 millones de direcciones Web" (Piscitelli, 2002, p. 128, n. 20), para una cifra de internautas que en la actualidad es sencillamente incalculable. La escritura electrónica se diferencia de la ordinaria o analógica en que no es secuencial, es decir, prefiere las múltiples voces y los múltiples planos, por eso su naturaleza es multimodal. La digitalización no solo cambió el soporte de escritura, sino que introdujo nuevas formas narrativas y orales (e-mail, chats, foros, redes sociales, etc.), nuevos sistemas de referencia, otros posicionamientos entre emisor y receptor, lo cual se traduce en distintas maneras de intentar y organizar la lectura y, por consiguiente, de interpretar el sentido (p. 125).

La tecnología, según Ramonet (2002, p. 9), ha permitido la integración de tres medios: la televisión, el teléfono y el ordenador (multimedia), de modo que en la pantalla del ordenador se integran, además de las funciones propias de la computadora, las de la red telefónica y las de la señal televisiva. A esto se agregan los nuevos dispositivos de la Internet, como el CD-Rom, el DVD o el videodisco digital (que al sustituir el videocasete va más allá de la utilización y grabación de películas) y, por supuesto, la webcam o cámara digital, que incorpora sonido e imagen. De modo que lo nuevo se relaciona con la alta capacidad de memoria (medida en gigas), la velocidad de la comunicación (banda ancha), la interconexión on-line, el surgimiento de nuevos formatos y tipos discursivos, entre otros. Estamos viviendo los tiempos de la multimodalidad y de la multimedialidad, la era de la globalización comunicacional e ideológica; por tanto, la escritura como sistema de modelización secundario ha sido rebasada por estas nuevas posibilidades electrónicas. Eso hace necesario encontrar 
un nuevo receptáculo, un nicho terminológico y epistémico para cobijar a todos los fenómenos que se dispararon después de la llegada del ciberespacio.

Pues bien, esta larga exposición sobre las maneras de representar la experiencia humana, que va de las pictografías a los bits de la escritura electrónica, permite comprender la complejidad de los sistemas de representación, pero aún no se ha puesto el suficiente énfasis en los conceptos de textualidad y de continuum cultural. Esto se hará en siguiente apartado.

\section{Escrituralidad, la otra categoría de la textualidad}

La producción textual humana, desde un punto de vista histórico, se articulaba entre dos categorías conceptuales: la oralidad y la escritura. Esto es lo que se había entendido hasta hace poco. Se trataba de una concepción restringida si se considera que, como se sabe, en la interacción social y en la semiosis posible (cfr. Peirce, 1974; Morris, 1962; Lozano, Peña y Abril, 1989) se genera toda una variedad de textos y discursos que desborda los estrechos límites de la escritura, lo que hace necesario recurrir a otro término, como es textualizar. Este término tendría la ventaja de integrar en él todas las modalidades de la producción discursiva. Schmidt (1977), el primer teórico de la lingüística del texto, lo entendió así: por una parte, existe la actividad semiótica de textualizar, entendida como la capacidad de producir e interpretar textos; por otra, la noción de textualidad, como el conjunto de todos los tipos de textos y discursos que una persona o una sociedad han sido capaces de producir.

El hombre ha sido siempre un textualizador, un productor de textos y discursos; por eso se alude a su pluralidad, a su hibridación consecuente, lo cual determina la preponderancia de ciertos tipos, más no la inexistencia de textos "puros", tal como se aprecia en la tabla 4:
Tabla 4. Clasificación de los textos

1. Textos predominantemente orales, producidos por el aparato fonador humano y los propalados y mezclados por algún medio radioeléctrico o telefónico.

2. Textos predominantemente escritos, resultado de la acción manual sobre un soporte de escritura o un aparato de impresión, desde la caña con la cual los sumerios y acadios hicieron la escritura cuneiforme, hasta el teclado de un ordenador o cualquier artilugio de impresión o digitalización.

3. Textos mixtos, en los cuales se combinan los dos sistemas anteriores, como, por ejemplo, un conferencista que redacta y lee y reescribe, corrige y vuelve a escribir, lo convierte en versión pdf o lo guarda como Power Point.

4. Textos audiovisuales: se caracterizan por combinar la voz, la escritura, la imagen (fija o en movimiento), banda sonora, canción, generador de caracteres, efectos especiales, imagen repetida o diferida, tal como ocurre en una emisión televisiva, una transmisión satelital, un video clip, un disco láser, etc.

5. Textos computarizados, producto de varias generaciones de artefactos cibernéticos y que se deben a la telefonía celular, los programas de informática, la inteligencia artificial, los multimedia, la animación computarizada, la tomografía axial, entre otros.

6. Textos semióticos: además de todas las clases de señales y productos contenidos en los cinco tipos anteriores, se debe agregar las especies aportadas por la semiótica de la Escuela de Tartu (Lotman y Escuela de Tartu, 1979), como una obra pictórica, una exposición de arte, un concierto, una pelea de box (vista en el mismo cuadrilátero o transmitida por satélite), un rito de iniciación, un filme, un juicio oral, un desfile militar, como actividades comunicativas e interactivas complejas.

En este apartado, asimismo, me interesaré por la manera como está organizada la producción textual, la cual fue introducida en el apartado sobre experiencias con la escritura, a propósito de la oralidad. Me centraré en la escrituralidad como el segundo constructo de la textualidad, pero lo haré a partir de una visión discursiva. Anteriormente, en el apogeo 
de la antropología funcional inglesa, se admitía que las tecnologías de la escritura habían producido un impacto en el desarrollo de la cultura occidental y que, por consiguiente, la cultura escrita se relacionaba directamente con la formación de organizaciones sociales complejas y con los procesos superiores del pensamiento (Cassany, 1999, pp. 222 y ss). En ese sentido, la "cultura escrita" (literacy, en inglés) representaba a "la cultura" y era considerada, a la vez, como algo que se diferenciaba de las condiciones subalternas de la "cultura oral”. Pero, según Cassany, se trataba de una "visión esquemática de la realidad", en la que "se reduce una realidad compleja a esquemas binarios de oposiciones, e incluso puede inducir a concepciones falsas y peligrosas por ser claramente eurocéntrica y discriminatoria. Sería absurdo asociar los términos civilización o ciudadano unilateralmente a la denominada cultura escrita y negarlos, por defecto, a las comunidades orales" (p. 225, el subrayado es del autor; énfasis agregado).

En años recientes la concepción eurocéntrica ha dado paso a una interpretación más justa que diferencia entre culturas dominantes y dominadas. $Y$ en el dominio de la lingüística se asume un enfoque interactivo, discursivo y pragmático. Ya no se admiten posturas maniqueas, ya no se esgrimen interpretaciones reduccionistas. En lugar de una realidad definida y analizada dicotómicamente, se debe considerar la existencia de un continuum cultural donde los fenómenos se perciben en un espectro, sin más diferencias que los matices o grados de pertenecer a la oralidad o a la escrituralidad. Se acepta, más bien, la tesis de la variación. Por eso es necesario postular la existencia de una nueva categoría que recubra la otra parte del continuum y dicha categoría es la de escrituralidad, que la propuse por primera vez en 1986 y la continué tratando en 1989, 1997 y 1999 (véase).

La escrituralidad está formada por todos aquellos productos que se crean y circulan en el contexto de las tecnologías de la escritura, la textualización y la digitalización; por tanto, obedece a pautas institucionales, dependientes de los "aparatos ideológicos del estado”. De ahí que la intervención de la tecnología sea decisiva: uso de lenguajes artificiales, multimedia, por un lado, y mayor poder difusivo, mayor capacidad de traducción intersemiótica y nuevas modalidades de dominación, por otro (Capriles, 1984). Su campo, por ende, está integrado por fenómenos tan diversos como las instituciones educativas, los productos industrializados, la cultura masificada, los estereotipos, mitos e ideologizaciones urbanos, el ciberespacio, los certámenes científicos y de entretenimiento, las editoras y las bibliotecas, el discado directo, en fin, un número ilimitado y sorprendentemente cambiante de fenómenos culturales. Dentro de este dominio y para entender la interacción entre escrituralidad y oralidad, revisaremos la teoría del continuum cultural.

\section{La teoría del continuum cultural}

En un principio la idea del continuum cultural (Mostacero, 1986) me permitió relacionar fenómenos de la "literatura oral-tradicional" con productos de la oralidad, incluso con aquellos que en la dinámica social se podían transformar en "escritos" y, nuevamente, volver a ser orales; pero al ir de la literatura a otras formas de textualización se vio la necesidad de incluir objetos de otra naturaleza. Por eso, el continuum puede ser espacial, temporal, social, histórico, en una palabra, cultural, e incluye elementos materiales e inmateriales, conceptuales e ideológicos.

Al comparar los fenómenos de la realidad con los de la ciencia, se llega a la comprobación, muy conocida, de que los primeros se observan como magnitudes continuas, mientras que los segundos se conciben como magnitudes discretas. Es decir, como objetos diferenciables. El científico aísla y define elementos, estudia sus relaciones e inventaría 


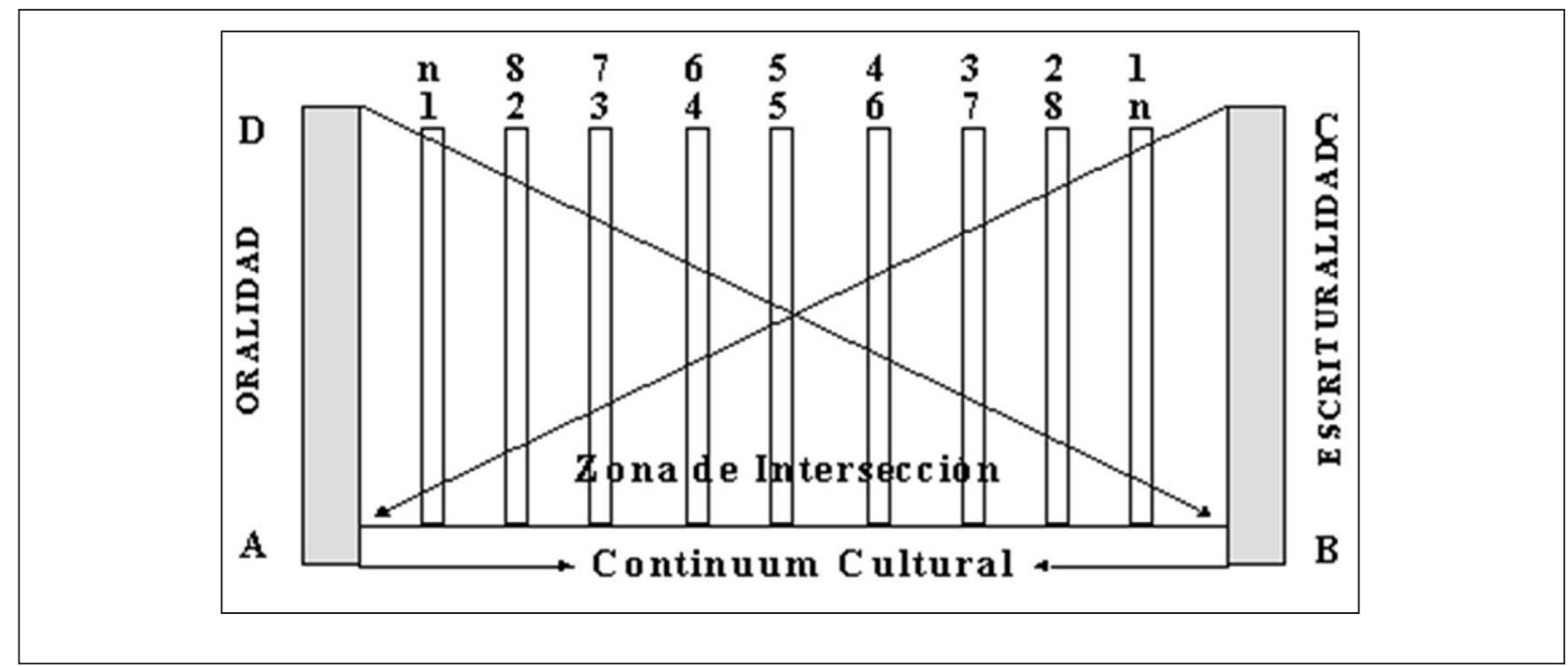

Figura 2. Esquema de un continuum cultural

su campo. Segmenta, clasifica y explica, concede jerarquías y determina niveles. Independiza variables y variantes, construye tipologías, sistemas y modelos. Esto es lo que ocurrió durante el desarrollo de la lingüística estructuralista, lo cual se proyectó, posteriormente, en el generativismo. Después de 1960 surge una opción distinta, ya que donde se había impuesto ver, invariablemente, "identidades vs. diferencias", se pasó a considerar que la cultura, la literatura y los fenómenos sociales en general son más bien variables, que en lugar de magnitudes definidas y analizadas binariamente se debía considerar la existencia de un continuum. Aquí los fenómenos se dan dentro de un espectro, sin más diferencias que los distintos grados o matices de ser variables e híbridos.

Es la teoría del continuum cultural (me referí a ella, por primea vez, en Mostacero, 1986). Las teorías lingüísticas de las últimas décadas se basan en concepciones etnográficas e interdisciplinarias, discursivas o interactivas, pero en todas predomina el punto de vista de la existencia de una interface o continuum, cuyos dos términos polares son los constructos de los que hemos venido hablando: oralidad y escrituralidad, tal como se aprecia en la figura 2 :
Donde $\mathrm{A} \rightarrow \mathrm{B}$ es el rango de variación en el continuum y los números inscritos dentro de él representan, en ambos sentidos, las variedades tanto de la oralidad como de la escrituralidad. La convergencia de las líneas oblicuas, que van, primero, en la dirección $\mathrm{C} \rightarrow \mathrm{A}$ y, luego, en la dirección $\mathrm{D} \rightarrow \mathrm{B}$ indica la penetración de un polo en el otro, mientras que en la parte inferior y central aparece la zona de intersección, lugar donde las variedades se mezclan, se vuelven híbridas $y$, por tanto, se transforman.

En el polo $\mathrm{A} \rightarrow \mathrm{D}$, que es el dominio de la oralidad, las variedades que están más próximas a él tendrán una naturaleza más característicamente oral, pero en la medida que se aproximan al polo contrario van dejando de serlo y adquieren los rasgos del polo opuesto. A este fenómeno se llama escrituralización. El polo B $\rightarrow$ C, o ámbito de la escrituralidad, contiene los elementos que le corresponden, pero al proyectarse al extremo opuesto se oralizan, recibiendo el nombre de oralización. La posibilidad de que existan deslizamientos se debe a su naturaleza social, lo cual, además, genera hibridación (cfr. Cornejo, 1982; Rama, 1984; Martín-Barbero, 1984; García, 1985). Precisamente donde la hibridación es mayor es en la zona de intersección, de modo 
que los fenómenos semióticos se deben analizar no por sus diferencias, sino por sus interrelaciones. Una ampliación de la teoría del continuum, en lo relativo a las marcas de oralidad en la escritura o las marcas de escritura en la oralidad, puede leerse en Mostacero (2006).

En el artículo "Lo escrito desde el análisis del discurso" Cassany dice que: "las causas o las circunstancias por las que lo hablado y lo escrito se entremezclan pueden ser variadas: particularidades del canal o condiciones de producción o recepción (escrito para ser escuchado, dicho para ser leído, etc.; Payrató, 1998: 29), idiolecto del autor (Tusón, 1991, p. 14), interferencias y citaciones polifónicas entre textos, etc." (1999, p. 225). Para, más adelante concluir diciendo:

... lo oral y lo escrito comparten un mismo espacio, que es el de la comunicación en la comunidad de hablantes de una lengua, $[y]$ expresan formas culturales complementarias y se recanalizan y transforman entre sí de modo continuo: se escribe lo oral para poder ser recordado, se ejecuta oralmente lo escrito en contextos particulares, etc. De este modo, oralidad y escrituralidad constituyen formas complementarias de expresar las distintas manifestaciones culturales de una comunidad compuesta por personas con distintas experiencias y formaciones comunicativas (p. 226).

Igualmente, en este artículo Cassany concedió una cita a la teoría del continuum, al referirse al tercero de mis trabajos sobre el tema (Mostacero, 1997), donde había refundido las ideas de 1986 y 1989. Eso indica que este autor no solo la comparte, sino que la vincula con otros autores que cita, por ejemplo: Halliday, Oesterreicher, Payrató, Tusón, Raible (Cassany, 1999, pp. 223-227).

Este planteamiento, se cree, no solo contribuye a redefinir, como lo hice en 1986, las literaturas oralestradicionales, en el marco de las culturas dentro del capitalismo, tesis de García Canclini (1982), sino que en la actualidad resulta muy apropiado para explicar los casos de heteroglosia, polifonía o multimodalidad que como teorías discursivas permiten referirse a la hibridación de textos y discursos. Si la textualidad humana abarca un conjunto de sistemas de textualización que van de la oralidad a la escrituralidad, entonces, la teoría del continuum cultural resulta apropiada para estudiar sus transformaciones. Asimismo, el fundamento ideológico de la oposición entre culturas dominantes y dominadas no se pierde, ya que se mantiene tanto en el plano de su origen y conformación, como variedades culturales, como en el plano de su significación ideológica. Los casos de transferencia semiótica se analizarán en el siguiente apartado.

\section{Tecnologías de la comunicación, coloquialismo y textualización}

En este apartado y a propósito de las tecnologías de la comunicación, vuelvo sobre el tema inicial de este trabajo, oralidad y escritura, solo que ahora lo plantearé desde otra perspectiva: la relación entre coloquialismo y textualización, que permite explicar los casos de transferencia de un campo a otro en la llamada dimensión semiótica de la cultura.

Mientras la oralidad la poseen, por naturaleza, todos los individuos, la escritura es una excepción. Un alto porcentaje de la población mundial es analfabeta o analfabeta funcional, y a pesar de las tecnologías del texto y de la imagen (satélites artificiales, fibra óptica, láser, microchips, telefonía celular, DVD, modem, webcam, entre otros). Pero, muy a pesar de la tecnología, siempre es posible distinguir una comunicación espontánea o primaria y una comunicación transferida o desplazada. Sirva el siguiente cuadro para ilustrar estas diferencias:

La tabla 5 permite explicar los casos de transferencia que en la Figura 1 solo habían sido mencionados y 
Tabla 5. Transferencia e intercambio de situaciones comunicativas.

\begin{tabular}{|c|c|c|}
\hline $\begin{array}{l}\text { COMUNICACIÓN } \\
\text { ESPONTANEA }\end{array}$ & $\begin{array}{l}\text { Transferencia de } A \text { en el ambiente de } B \text { o } \\
\text { viceversa. }\end{array}$ & $\begin{array}{l}\text { Intercambio de situaciones dialógicas } \\
\text { y contextuales. }\end{array}$ \\
\hline $\begin{array}{l}\text { ORALIDAD } \\
\text { PRIMARIA } A\end{array}$ & $\begin{array}{l}\text { Oralidad a partir de la escritura. } \\
\text { ORALIZACIÓN de textos escritos. }\end{array}$ & $\begin{array}{l}\text { Ejemplos: } \\
\text { - Leer un poema. } \\
\text { - Leer y exponer el texto de una ponencia escrita. } \\
\text { - Informar acerca del contenido de un libro leído. }\end{array}$ \\
\hline $\begin{array}{l}\text { ESCRITURA } \\
\text { PRIMARIA } B\end{array}$ & $\begin{array}{l}\text { Escritura a partir de textos orales. } \\
\text { EsCRITURACIÓN de textos orales. }\end{array}$ & $\begin{array}{l}\text { Ejemplos: } \\
\text { - Copiar un mensaje hablado. } \\
\text { - Transcribir una conversación grabada. }\end{array}$ \\
\hline
\end{tabular}

estaban ubicados en la zona de intersección, donde los fenómenos de uno y otro polo se transmutan, se vuelven híbridos. Mientras que en la comunicación espontánea lo oral y lo escrito son solo eso: formas comunicativas sin mezclas ( $A$ y $B$ en la primera columna), la segunda columna se refiere a los casos de transferencia de $A$ en el ambiente de $B$, o viceversa. $\mathrm{Al}$ respecto, Cervera dice:

Se acepta que en los textos escritos permanece el habla, como forma de comunicación en el tiempo y en el espacio reflejado por un solo sujeto. Cabe, entonces, hablar de textualización en el discurso conversacional cuando se recurre a la codificación del texto oral a rasgos textualizadores de carácter gramatical, semántico y pragmático, como construcción sintáctica, fraseológica, variedad léxica, precisión, referencia y deixis. Esta visión textualizadora [...] permitirá hablar de discurso oral textualizado (2002, p. 4).

El mismo autor dice que en la escritura hay rasgos coloquializadores y en el habla oral rasgos textualizadores. Su definición y explicación pertenece a la pragmática: "En cualquiera de los actos de habla pueden aparecer rasgos coloquializadores (Briz y otros, 1998, p. 2), aunque hay grados de coloquialidad textual con independencia de la modalidad o género utilizado. Nace así el texto escrito oralizado" (Cervera, 2002, p. 4). Además, añade, este autor, las variedades pueden aproximarse o distanciarse de su matriz originaria dependiendo del "grado de coloquialidad o textualidad que contengan en cada momento" (p. 4).

Lo anterior permite comprender dos cosas: primero, que lo oral se transforma en texto escrito y, su contrario, que lo escrito se plasma en texto oral, gracias a la mayor o menor cantidad de elementos de textualización o de coloquialización, respectivamente; $y$, segundo, que de aquí se deriva la existencia de marcas o huellas que se pueden rastrear en el texto transformado, que son marcas de hibridación. La indagación de esta parte de la teoría de la textualidad está en sus inicios, aun cuando algunos autores ya han advertido su existencia y hasta han hecho investigaciones históricas, por ejemplo Oesterreicher (1998), quien a la vez reporta estudios europeos y norteamericanos (especialmente, Tannen).

Oesterreicher introduce la distinción entre "oralidad o lengua hablada" y "escrituralidad o lengua escrita" y es uno de los pocos que usa el término "escrituralidad", por lo menos según el traductor. 
La traducción del libro donde se dio a conocer su artículo "Lo hablado en lo escrito. Reflexiones metodológicas y aproximación a una tipología”, es de 1998 y apareció en el número 1 de la revista Oralia. Oesterreicher identifica "lo fónico" y "lo gráfico" como una dicotomía, mientras que "lo hablado" y "lo escrito" se dan por relación escalar, entre dos extremos, pero dentro de un continuum (1998, p. 318) y se puede entender como un registro que va desde una conversación muy íntima hasta la formalidad del código jurídico.

En síntesis, este autor nos proporciona la evidencia de que algunos investigadores ya se habían interesado por las relaciones entre lo oral y lo escrito, habían advertido la existencia del continuum y los casos de transferencia, por ejemplo, Giovanni Nencioni (en 1976), Elinor Ochs (en 1979), Deborah Tannen (en 1980), Meter Koch y Wallace Chafe (en 1985), Douglas Biber (en 1988). Eso indica que los estudios de oralidad versus escrituralidad no son $\tan$ recientes, aunque sus noticias se hayan conocido, tardíamente, en lengua española. Y en España los aportes más descollantes se deben al grupo VaLesCo de la Universidad de Valencia que dirige Antonio Briz (cfr. 1995; 1998; Briz y otros, 1997).

Para nuestro país se reportaron, sobre todo, comunicaciones a congresos, como el caso de mi primera ponencia, titulada "La literatura en el continuum cultural: una propuesta de definición" de 1986, seguida de otra: "Para una redefinición del campo cultural: oralidad y escrituralidad", de 1989, donde avancé desde la definición de literatura oral a la tesis de la semiosis cultural, y, por último, en 1990, al escribir el primer capítulo de un libro que fue presentado a una bienal y que siete años después apareció publicado en Caripe: historia cotidiana y oralidad $^{2}$. Empero, el primer venezolano que estudió las marcas de oralidad en textos de ficción fue Carlos Pacheco (La comarca oral, 1992), lo que denominó "la ficcionalización de lo oral", y fue analizada en obras de Juan Rulfo y João Guimarães Rosa. Y, más recientemente, pero esta vez en textos académicos, las marcas de oralidad, pero en la exposición de una ponencia, han sido indagadas por Larrauri (2001).

Lo acabado de reseñar indica que tanto en Venezuela como en otros países las teorías y sus aplicaciones solo estaban, por esos años, en su fase inicial, pero es oportuno actualizar la información. En la medida en que el análisis del discurso y la pragmática profundicen sus análisis, se contará con recursos para investigar en tantos continua como áreas de interacción existen: de la escritura analógica a la digital, de la científica a la de divulgación, de la cinematográfica a la conversacional, del relato oral a la narración literaria, para mencionar solo algunas. Para no dejar ningún cabo suelto, cerraré este artículo con una última sección donde relaciono oralidad, escritura y alfabetización.

\section{Oralidad, escritura y alfabetización}

En cada uno de los apartados de este artículo examiné las múltiples relaciones que contraen los dos grandes constructos de la experiencia humana, la Oralidad y la Escrituralidad. Presenté las formulaciones teóricas que son necesarias para poder explicar cómo operan dentro de la semiosis y en

2 En 1990 Domingo Rogelio León y yo presentamos el libro Caripe: historia cotidiana y oralidad al concurso convocado por la Universidad de Oriente (Cumaná) y ganó el primer premio, mención Testimonio, de la Novena Bienal de Literatura "José Antonio Ramos Sucre". El primer capítulo contenía una refundición y una ampliación de todo cuanto había escrito hasta ese año sobre la teoría del continuum, y solo en 1997 apareció publicado, con el mismo título, en la colección Guanipa de la Biblioteca de Temas y Autores Monaguenses. 
relación con otras prácticas comunicativas, como pictografiar, grafizar, textualizar y digitalizar. Establecí sus campos específicos y de qué manera las variedades que contienen se articulan dentro del continnum cultural; enumeré los sistemas históricos de escritura y las escrituras especiales y los sistemas notacionales y de grafización; propuse una clasificación de los textos y, finalmente, analicé las tecnologías de la comunicación, la textualización y el coloquialismo. Sin embargo, no he dicho nada sobre los usos y funciones que la oralidad y la escritura tienen en situaciones concretas de aprendizaje.

Eso es necesario ya que toda práctica discursiva posee dos contextos naturales de uso: el contexto cotidiano y el educativo. En el discurso cotidiano prevalece el uso coloquial, espontáneo y polilectal, inducido por las diferencias sociales, espaciales y culturales de los hablantes, mientras que en el discurso formal o escolar el uso se relaciona con las modalidades discursivas, con los géneros, con las estrategias de aprendizaje, con la adquisición del conocimiento, entre otros. El discurso adopta una dimensión académica y epistémica y requiere de la intervención de dos clases de mediadores: el lenguaje, que media entre la realidad y los hombres, $y$ el docente, que lo hace entre el saber y el educando.

Pues bien, considerando la segunda instancia de mediación, en este último apartado me interesa abordar, entre muchos tópicos, solamente dos: las relaciones que la oralidad y la escritura tienen con los procesos de alfabetización y de qué manera el trabajo de revisión y corrección textual que se hace con la escritura tiene un correlato con la reformulación y la corrección que el hablante aplica durante su actuación oral.

La oralidad y la escritura como constructos semióticos tienen una relación muy estrecha con los tipos de alfabetización. Si esta puede ser identificada y definida por las necesidades humanas que atiende, es decir, por las exigencias de la socialización y la inserción del ser humano en la cultura, entonces se consideran cuatro tipos de alfabetización: a) la inicial, con el aprendizaje de las primeras letras y las primeras cifras; b) la intermedia o secundaria, cuando el conocimiento adquirido va de la escuela básica a la secundaria; c) la académica o terciaria, que depende esencialmente de una cultura muy especializada y orientada a las profesiones; y d) la digital o tecnológica, supeditada al aprendizaje de usos y funciones con medios y dispositivos de carácter digito-visual.

Mientras que la alfabetización inicial depende del contexto familiar y preescolar, sin mayores requerimientos de enseñanza formal, los restantes tipos sí los necesitan. Por ejemplo, la adquisición de competencias pragmáticas y discursivas para leer y redactar textos de gran complejidad estructural y cognitiva. Se precisa de una cultura muy especializada (conocimiento experto) y de un mediador que haya sido formado en un modelo pedagógico innovador. Sin embargo, en nuestro medio los estudiantes que son promovidos a la universidad no han sido iniciados ni en la cultura universitaria ni en la alfabetización específica de cada carrera.

Por otra parte, los diseños curriculares universitarios tampoco están preparados para transmitir el saber y las prácticas de una cultura que está en franco proceso de digitalización. Por lo mismo, los alumnos están obligados a optar por un autoaprendizaje o por un aprendizaje compulsivo. Además, desde el punto de vista del aprendizaje significativo tienen que desarrollar competencias: primero, para apropiarse de los contenidos disciplinares; segundo, para asimilar y aplicar las estrategias de lectura y escritura que demandan los géneros discursivos complejos; y tercero, en el caso de los docentes, para conocer y aplicar estrategias que sean idóneas para enseñar a otros. 
No obstante, en nuestras universidades no existen diseños apropiados ni para formar a los docentes ni para que estos puedan transferir la enseñanza. ¿Por qué no se cumple esta meta? Porque los diseños y las prácticas son tradicionales. Están anclados en una concepción magistrocentrista, donde el estudiante se limita a una respuesta pasiva y receptiva (Carlino, 2007; Mostacero, en prensa). Por tanto, si el modelo es tradicional y posee una inequívoca identificación con las teorías conductistas o con la teoría de la escritura como producto (Cassany, 1999; Ortiz, 2009; Carlino, 2004; 2009; Mostacero, 2011), entonces se justifica suplantarlo por un modelo transformador, pero para que esto se pueda dar se requiere que las autoridades ministeriales y rectorales asuman la responsabilidad institucional del cambio y que las innovaciones curriculares se apliquen en todos los niveles y de manera coherente.

Al considerar, ahora, cómo se produce el trabajo de revisión y corrección textual tanto en el discurso oral como en el escrito, empezaré diciendo que en el primero se trata de una reformulación discursiva que el hablante ejecuta a partir de su escucha y de la conciencia sintáctica que como enunciador hace dentro de la construcción de su discurso. Domínguez (2005) demuestra que en la construcción del discurso oral tenemos hesitaciones, arranques en falso, cambios de tópico, de modalidad o de estrategias, etc., debido a que el tempo de la planificación se superpone al de la enunciación, de tal manera que se necesita hacer reformulaciones constantes, basadas en repeticiones, alargamiento de palabras o sílabas, silencios, cambios abruptos de estrategias, entre otros.

Esto se puede comprobar en el siguiente fragmento de un relato oral que una estudiante de pregrado grabó a un compañero de estudios. Ambos son estudiantes bogotanos de 18 a 20 años y la grabación se hizo en el salón de clase, pero se hace referencia a un suceso que le ocurrió a él con su novia en el Parque Nacional de Bogotá. En el texto que sigue se han incorporado entre paréntesis las abreviaturas de los siguientes fenómenos de reformulación, siguiendo la terminología de Domínguez (2005)

//Mmm (H) bueno dos (AF) de los momentos más felices de mi vida pasaron, el mismo día el día (RP) que que salíii (RP y AF) por primera vez con mi novia. El primero ess... (H, A y AF) cuandoo fuimos (AF) al parque nacional y, ahí noss (AF) recostamos debajo de un árbol, y no sé empezamos a hablar y hablar, y de un momento a otro nos quedamos dormidos... (H) no fue mucho tiempo y fue muy hermoso. Yo me acuerdo que era un sábado por la tarde yy... (H y A) no sé fue muy lindo, porque (AF) hubo un atardecer, yyy (AF) lo vimos y fue fue (RP) muy chévere. Después de eso $\mathrm{mmm}(\mathrm{H})$ cuando ya nos íbamos a ir para la casammm (H) le dije que fuéramos a la estación Flores y ahí le, le (RP) propuse que nos casáramos perooo ( $\mathrm{AF}$ ) un matrimonio simbólico, porque ese día era la primera vez que salíamos yy (AF), y porqueee (AF) nunca nos nunca nos habíamos dado un beso y es más ese día ese día (RP), el día (RT) que nos casamos no nos besamos me dio miedo... $(\mathrm{H})$ besarla, ee $(\mathrm{H})$ le dije que nos casáramos y ella me regaló una joya muy, muy valiosa (RP) queé (AF y H) que nunca (RP) se había atrevido a darle a nadie, y que se lei (A) que se le (A) que ella ella (RP) me dijo que se lo iba a dar a alguien, en quien confiara mucho yy (AF) me la dio y o sea $(\mathrm{H})$ llevábamos mucho (A) muy poquito tiempo de, no conocernos (A) fue muy hermoso y ya esos son mis momentoss felices//

Mientras que en el discurso oral la planificación es simultánea con la construcción del texto, en el escrito no, porque se puede corregir, se puede borrar, rehacer. Por eso Domínguez afirma:

3 El fragmento oral insertado posee otra fuente para diferenciarlo del resto de las citas. En el relato transliterado utilicé $\mathrm{H}$ para una duda o hesitación, RP para repeticiones, $\mathrm{C}$ para correcciones, A para arranques en falso y RT para retrocesos. Esto es de acuerdo con la autora ya citada, y agrego AF para el alargamiento fonético. 
Una característica del uso oral de la lengua es el hecho de que, en su producción, este obliga a que la planificación y la realización del texto sean prácticamente simultáneas. De esta manera el rasgo que puede considerarse definitorio de este uso es precisamente el hecho de que el texto oral muestra las huellas de la planificación textual. El hablante hesita, retrocede, corrige, repite, en el curso de su expresión, [y] no puede ser de otra manera (2005, p. 102).

Lo que la Real Academia de la Lengua ha convalidado como errores, vicios, incorrecciones, faltas, etc., para el código escrito, carece de las mismas aplicaciones para el uso oral. De hecho, en el habla coloquial no existen tales errores, solo reformulaciones o cambios de estrategias enunciativas, y esto debería ser algo que del plano oral se traslade al plano escrito para cambiar la inadecuada concepción que aún prevalece en la corrección escrita escolar.

Pues bien, habiendo llegado al final de esta exposición, es necesario recoger las redes. Mi propósito era deslindar oralidad de escritura y construir un nicho epistémico para la escrituralidad. Ya está construido y en él residen varias clases de sistemas, desde los sistemas históricos de escritura hasta sus formatos digitales. Lo cierto es que a lo largo y ancho del continuum he demostrado que la oralidad cabalga todas las manifestaciones de la semiosis, tanto de la real como de la posible, y que, por tanto, no se disuelve en el entramado de la escrituralidad, ni esta en aquella. Sucede, más bien, que surgen fenómenos de desplazamientos y transferencias y que la tarea del semiótico, del analista del discurso o del pedagogo de la lengua, es aprovechar las propuestas de modelización científica para comprender los casos de hibridación textual y discursiva y poder aplicarlos en los entornos escolares. Eso significa que el futuro de la investigación es interesante y está asegurado.

\section{Bibliografía}

Briz, A. (coord.) (1995). La conversación coloquial. Materiales para su estudio. Cuadernos de Filología, anejo XVI. Universidad de Valencia.

Briz, A. et ál. (eds.) (1997). Pragmática y gramática del español hablado. El español coloquial. Zaragoza: Pórtico.

Briz, A. (1998). El español coloquial en la conversación. Esbozo de una pragmagramática. Barcelona: Ariel.

Capriles, O. (1984). Comunicación y cultura en el reino del Big Brother. Nueva Sociedad, 71, 42-54.

Cardona, G. R. (1999). Antropología de la escritura. Barcelona: Gedisa.

Carlino, P. (2004). ¿De qué modo incentivar en nuestras instituciones la responsabilidad compartida por cómo se lee y se escribe en la universidad/ IFD. I Congreso Internacional Educación, Lenguaje y Sociedad, Santa Rosa de La Pampa, Universidad de La Pampa, Argentina.

Carlino, P. (2007). Escribir, leer y aprender en la universidad. Una introducción a la alfabetización académica. Buenos Aires: Fondo de Cultura Económica.

Carlino, P. (2009). Desarrollo profesional de docentes para leer y escribir a través del currículum. En: P. Carlino y S. Martínez (coords.), La lectura y la escritura, un asunto de todos. Neuquén: Universidad Nacional del Comahue.

Cassany, D. (1999). Lo escrito desde el análisis del discurso. Lexis, XXIII(2), 213-242. 
Cassany, D. (2002). De lo analógico a lo digital. El futuro de la enseñanza de la composición. Textura, 1(1), 9-17.

Cervera, Á. (2002). La irrupción del coloquialismo en Internet y las nuevas tecnologías. II Congreso Internacional de la Lengua Española, Centro Virtual Cervantes, Instituto Cervantes (España).

Cornejo Polar, A. (1982). Sobre literatura y crítica latinoamericana. Caracas: Universidad Central de Venezuela.

Desbordes, F. (1995). Concepciones sobre la escritura en la antigüedad romana. Barcelona: Gedisa.

Domínguez, C. L. (2005). Sintaxis de la lengua oral. Mérida, Venezuela: Consejo de Desarrollo Científico, Humanístico y Tecnológico de la Universidad de Los Andes.

Eco, U. (1976). Signo. Barcelona: Labor.

Eco, U. (1980). Tratado de semiótica general. Barcelona: Lumen.

Eco, U. (2000). Los límites de la interpretación. Barcelona: Lumen.

García Canclini, N. (1982). Las culturas populares en el capitalismo. México: Nueva Imagen.

García Canclini, N. (1985). Cultura trasnacional y culturas populares en México. México. Mimeo.

Goody, J. (comp.) (1996). Cultura escrita en sociedades tradicionales. Barcelona: Gedisa.

Greimas, A. J. (1971). Semántica estructural. Madrid: Gredos.

Landow, G. (1995). Hipertexto. La convergencia de la teoría crítica contemporánea y la tecnología. Barcelona: Paidós.
Larrauri, A. (2001). Oralidad en un texto escrito para ser leído frente a una audiencia. Inédito.

Lewandowski, T. (1992). Diccionario de lingüística. Madrid: Cátedra.

Lozano, J. Peña, C., y Abril, G. (1989). Análisis del discurso. Hacia una semiótica de la interacción textual. Madrid: Cátedra.

Lotman, I. y Escuela de Tartu (1979). Semiótica de la cultura. Madrid: Cátedra.

Martín-Barbero, J. (1984). Cultura popular y comunicación de masas. Materiales para la Comunicación Popular, 3. Lima.

Morris, C. (1962). Signos, lenguaje y conducta. Buenos Aires: Losada.

Mostacero, R. (1986). La literatura en el continuum cultural: una propuesta de definición. XII Simposio de Docentes e Investigadores de la Literatura Venezolana, Maturín, Instituto Pedagógico de Maturín.

Mostacero, R. (1989). Para una redefinición del campo cultural: Oralidad y Escrituralidad. XIV Simposio de Docentes e Investigadores de la Literatura Venezolana, Caracas, Instituto Pedagógico de Caracas.

Mostacero, R. (1999). Oralidad, escritura y escrituralidad. Jornadas de Lectura y Escritura del Instituto Pedagógico de Caracas, 20-22 de octubre.

Mostacero, R. (2004). Oralidad, escritura y escrituralidad. Sapiens 5(1), 53-75. Caracas, Universidad Pedagógica Experimental Libertador, Instituto Pedagógico de Miranda J. M. Siso Martínez.

Mostacero, R. (2006). Del fonema al texto: necesidad de una teoría del continuum. Memoralia, 3, 133-146. 
Mostacero, R. (2011). La escritura académica como discurso experto y como política de ingreso a la universidad. En F. J. Bolet (comp.). Discurso y educación (Foro), Cuadernos ALED-Venezuela (no. 1, pp. 9-26). Caracas: Delegación Regional de Venezuela.

Mostacero, R. (en prensa). Dificultades de escritura en el discurso académico: análisis crítico de una situación problemática. Legenda (arbitraje). Universidad de Los Andes, Mérida.

Mostacero, R. y D. R. León (1997). Caripe: historia cotidiana y oralidad. Maturín: Biblioteca de Temas y Autores Monaguenses.

Mounin, G. (1972). Introducción a la semiología. Barcelona: Anagrama.

Oesterreicher, W. (1998). Lo hablado en lo escrito. Reflexiones metodológicas y aproximación a una tipología. Oralia, I, 317-340.

Olson, D. y N. Torrance (comps.) (1998). Cultura escrita y oralidad. Barcelona: Gedisa.

Ong, W. (1987). Oralidad y escritura: tecnologías de la palabra. México: Fondo de Cultura Económica.

Ortiz Ocaña, A. (2009). Manual para elaborar el modelo pedagógico de la institución educativa. Bogotá: Antillas.

Pacheco, C. (1992). La comarca oral. Caracas: La Casa de Bello.
Peirce, C. S. (1974). La ciencia de la semiótica. Buenos Aires: Nueva Visión.

Piscitelli, A. (2002). Ciberculturas 2.0. En la era de las máquinas inteligentes. Buenos Aires: Paidós.

Rama, Á. (1984). La ciudad letrada. Montevideo: Comisión Uruguaya pro Fundación Internacional Ángel Rama.

Ramonet, I. (2002). Una gran mutación. En I. Ramonet (ed.). La post-televisión. Multimedia, Internet y globalización económica. Barcelona: Icaria.

Rodríguez Ruiz, J. (1999). Hipertexto y literatura: una batalla por el signo en tiempos posmodernos. Bogotá: Centro Editorial Javeriano.

Rossi-Landi, F. (1976). Semiótica y estética. Buenos Aires: Nueva Visión.

Sampson, G. (1997). Sistemas de escritura. Barcelona: Gedisa.

Schaff, A. (1966). Introducción a la semántica. México: Fondo de Cultura Económica.

Schmidt, S. (1977). Teoría del texto. Madrid: Cátedra.

Tolchinsky, L. (1993). Aprendizaje del lenguaje escrito. Barcelona: Anthropos.

Tusón, J. (1997). La escritura. Una introducción a la cultura alfabética. Barcelona: Octáedro. 